H PYLORI ERADICATION AND GORD: VIEWPOINT 1

\title{
Effect of Helicobacter pylori eradication on the treatment of gastro-oesophageal reflux disease
}

\section{J E Richter}

Gut 2004;53:310-311

The important issue of whether Helicobacter pylori eradication leads to increased reflux has been the subject of many apparently contradictory publications, but when we asked two leading authorities to give us their views, there turned out to be considerable consensus, as you can read below.

Correspondence to: Professor J E Richter, The Cleveland Clinic Foundation,

Gastroenterology and Hepatology, Cleveland OH 44195, USA; richtej@ccf.org

Accepted for publication 1 July 2003
A lthough the prevalence of Helicobacter pylori nations, over the same time gastrooesophageal reflux disease (GORD) and its complications have increased in Western countries. $^{1}$ GORD affects $25-40 \%$ of the population ${ }^{2}$ and Barrett's oesophagus and oesophageal adenocarcinoma are being recognised at an increasingly alarming rate. ${ }^{1}$ This has led to the suggestion that $H$ pylori is the possible aetiological factor for this changing epidemiology.

Most studies find no evidence that $H$ pylori infection causes GORD. ${ }^{3}$ Rather, some but not all studies have found a lower prevalence of $H$ pylori infection in patients with reflux symptoms or oesophagitis, suggesting a possible protective effect of this bacteria. ${ }^{4-7} \mathrm{~A}$ recent systematic review of the literature suggests that geography is an important factor complicating this relationship. Raghunath and colleagues ${ }^{8}$ evaluated 20 studies and found that the pooled estimate of the odds ratio for the prevalence of $H$ pylori in patients with GORD was 0.60 (95\% confidence intervals (CI) 0.47-0.78). The evidence for this protective relationship in Europe was equivocal, but consistent evidence was found for a lower prevalence of $H$ pylori among both North American (odds ratio 0.70 (95\% CI 0.55-0.90)) and Far Eastern (odds ratio 0.24 (95\% CI 0.190.32)) patients with GORD.

$H$ pylori infection can have a variable effect on acid secretion, depending on the type and distribution of gastritis. ${ }^{9}$ Non-atrophic predominantly antral inflammation results in hypergastrinaemia and acid hypersecretion; this pattern is prevalent in patients with duodenal ulcer disease. In contrast, patients with corpus predominant gastritis have decreased acid secretion, which is the predominant pattern in patients with gastric ulcers or gastric cancer. Eradication of the organism is associated with correction of these abnormalities in both types of gastritis. However, the majority of $H$ pylori infected patients without disease have a mixed pattern of gastritis, whereby the elevated gastrin resulting from antral inflammation fails to cause is steadily decreasing in industrialised gastric acid secretion because of corpus inflammation.

The effect of $H$ pylori eradication on 24 hour oesophageal acid exposure is variable. Two studies $^{10}{ }^{11}$ in patients with $H$ pylori gastritis found no changes in 24 hour oesophageal acid exposure before and 12 weeks after eradication therapy. On the other hand, Feldman and colleagues $^{12}$ found that three of nine asymptomatic gastritis patients developed pathological acid reflux after $H$ pylori eradication. In another study, Wu and colleagues ${ }^{13}$ investigated oesophageal acid exposure in 14 patients with GORD and $H$ pylori infection, who were randomised to receive eradication therapy, and 11 patients randomised to omeprazole alone. There was no difference in per cent time to oesophageal $\mathrm{pH}<4$ before and 26 weeks after treatment between the groups. However, the per cent time $\mathrm{pH}<2$ $(\mathrm{p}=0.01)$ and $\mathrm{pH}<3(\mathrm{p}=0.02)$ was significantly increased in patients receiving $H$ pylori eradication treatment. A small number of patients developed worsening oesophagitis $(n=3)$. Conclusions from these studies are difficult because sample sizes were small, the type and extent of gastritis was not assessed, and the prevalence and severity of GORD were rarely defined.

$H$ pylori infection may affect the action of proton pump inhibitors (PPI). Intragastric $\mathrm{pH}$ is consistently higher during PPI treatment in $H$ pylori infected patients than in either uninfected or eradicated patients. ${ }^{14}$ Is this clinically important as we treat our GORD patients with or without $H$ pylori infection? Holtzmann and colleagues $^{15}$ showed that patients with $H$ pylori infection treated with pantoprazole had better symptom relief and healing of oesophagitis at four and eight weeks than non-infected reflux patients. The effects were much less pronounced at eight weeks than at four weeks. However, four other studies found that $H$ pylori status did not adversely effect treatment results with PPI. Carlsson and colleagues ${ }^{16}$ studied 1350 patients with GORD treated with omeprazole and found that symptom relief and healing rates were similar in patients with $H$ pylori infection and those who were not infected. Vakil and colleagues $^{17}$ likewise showed that $H$ pylori infection did not affect healing rates in erosive oesophagitis treated with esomeprazole. Peters and colleagues $^{18}$ treated 26 patients with Barrett's oeso-

Abbreviations: GORD, gastro-oesophageal reflux disease; PPI, proton pump inhibitors 


\section{Summary}

- The prevalence of $H$ pylori infection is significantly lower in patients with compared with those without gastro-oesophageal reflux disease.

- The mechanism of this protection is decreased acid secretion from corpus gastritis: this is reversible after $\mathrm{H}$ pylori eradication.

- After $H$ pylori eradication, the effects on distal oesophageal acid exposure are unpredictable.

- The vast majority of GORD treatment trials with proton pump inhibitors find that patients with and without $H$ pylori infection show no differences in symptom relief, healing of acute oesophagitis, or efficacy of maintenance regimens.

phagus (14 H pylori negative, $12 \mathrm{H}$ pylori positive) with omeprazole $40 \mathrm{mg}$ twice daily. Omeprazole resulted in a decrease in 24 acid reflux values from $23.4 \%(7.9-39.3)$ to $0 \%$ $(0.0-2.9)$ in $H$ pylori negative and from $17.3 \%(8.9-38.8)$ to $0.1 \%(0.0-1.7)$ in $H$ pylori positive patients. Symptoms were also equally controlled in each group. Finally, Schenk and colleagues ${ }^{19}$ showed that the dose of omeprazole required for maintenance after healing of erosive oesophagitis was similar in patients with and without $H$ pylori infection.

In summary, most treatment trials with PPI do not find that $H$ pylori status adversely affects symptom relief, healing of acute oesophagitis, or maintenance treatment of erosive oesophagitis. Therefore, clinicians should continue to eradicate $H$ pylori infection when found and not be concerned about aggravating possible coexisting reflux disease which should easily respond to PPI therapy.

\section{REFERENCES}

1 El Serag HB, Sonnenberg A. Opposing time trends of peptic ulcer and reflux disease. Gut 1998;43:327-33.
2 Jones R. Gastro-oesophageal reflux disease in general practice. Scand J Gastroenterol Suppl 1995;211:35-8.

3 Richter JE, Falk GW, Vaezi MF. Helicobacter pylori and GERD: the bug may not be all bad. Am J Gastroenterol 1998;93:1800-2.

4 Loffeld RJLF, Werdmuller BFM, Kuster JA, et al. Colonization with cagA positive Helicobacter pylori strains inversely associated with reflux esophagitis and Barrett's esophagus. Digestion 2000;62:95-9.

5 Vicari JJ, Peek RM, Falk GW, et al. The seroprevalence of cagA positive Helicobacter pylori strains in the spectrum of gastroesophageal reflux disease. Gastroenterology 1998;115:50-7

6 Fallone CA, Barkun AW, Friedman G, et al. Is Helicobacter pylori eradication associated with gastroesophageal reflux disease? Am J Gastroenterol 200;95:914-20.

7 Koike T, O'Hara S, Sekine H, et al. Helicobacter pylori infection prevents erosive reflux oesophagitis by decreasing acid secretion. Gut 2001;49:330-4.

8 Raghunath A, Hungin APS, Wooff D, et al. Prevalence of Helicobacter pylori in patients with gastro-oesophageal reflux disease: systemic review. BMJ 2003;326:737-9.

9 Labenz J, Malfertheiner P. Helicobacter pylori in gastro-oesophageal reflux disease: causal agent, independent or protective factor? Gut 1997; 41:277-80

10 Telfera S, Hatlebakk J, Berstad A. The effect of Helicobacter pylori eradication on gastro-oesophageal reflux. Aliment Pharmacol Ther 1999;13:915-20.

11 Manifold DK, Anggiansah A, Rowe I, et al. Gastroesophageal reflux and duodenogastric reflux before and after eradication in Helicobacter pylori gastritis. Eur J Gastroenterol Hepatol 2001;13:535-9.

12 Feldman M, Cryer B, Sammer D, et al. Influence of $H$. pylori infection on meal stimulated gastric acid secretion and gastroesohageal reflux. Am J Physiol 1999;277:G1159-64.

13 Wu JC, Chan FK, Wong SK, et al. Effect of Helicobacter pylori eradication on oesophageal acid exposure in patients with reflux esophagitis. Aliment Pharmacol Ther 2002;16:545-52.

14 Martinek J, Kuzela I, Spicak J, et al. Review article: The clinical influence of Helicobacter pylori in effective acid suppression-implications for the treatment of gastroesohageal reflux disease. Aliment Pharmacol Ther 2000; 14:979-90.

15 Holtmann G, Cain C, Malfertheiner P. Helicobacter pylori infection accelerates healing of reflux esophagitis during treatment with the proton pump inhibitor pantoprazole. Gastroenterology 1999;117:11-16.

16 Carlsson R, Bate C, Dent J, et al. Does H. pylori infection influence the response to treatment with acid inhibition in patients with GERD? Scand J Gastroenterol 1997;32(suppl 224):F70.

17 Vakil N, Kahrilas P, Magner D, et al. Does baseline H. pylori status impact erosive esophagitis healing rates? Am J Gastroenterol 2000;95:2438A.

18 Peters FTM, Kuipers EJ, Ganesh S, et al. The influence of Helicobacter pylori on oesophageal acid exposure in GERD during acid suppressive therapy. Aliment Pharmacol Ther 1999;13:921-6.

19 Schenk BE, Kuipers EJ, Klinbenberg-Knol EC, et al. Helicobacter pylori and the efficacy of omeprazole therapy for gastroesophageal reflux disease. Am J Gastroenterol 1999;94:1018-22. 